\title{
Numerical Solutions of the Generalized Burgers-Huxley Equation by a Differential Quadrature Method
}

\author{
Murat Sari $^{1}$ and Gürhan Gürarslan ${ }^{2}$ \\ ${ }^{1}$ Department of Mathematics, Faculty of Art and Science, Pamukkale University, 20070 Denizli, Turkey \\ ${ }^{2}$ Department of Civil Engineering, Faculty of Engineering, Pamukkale University, 20070 Denizli, Turkey \\ Correspondence should be addressed to Murat Sari, msari@pau.edu.tr
}

Received 29 July 2008; Accepted 26 January 2009

Recommended by Francesco Pellicano

Numerical solutions of the generalized Burgers-Huxley equation are obtained using a polynomial differential quadrature method with minimal computational effort. To achieve this, a combination of a polynomial-based differential quadrature method in space and a low-storage third-order total variation diminishing Runge-Kutta scheme in time has been used. The computed results with the use of this technique have been compared with the exact solution to show the required accuracy of it. Since the scheme is explicit, linearization is not needed and the approximate solution to the nonlinear equation is obtained easily. The effectiveness of this method is verified through illustrative examples. The present method is seen to be a very reliable alternative method to some existing techniques for such realistic problems.

Copyright ( 2009 M. Sari and G. Gürarslan. This is an open access article distributed under the Creative Commons Attribution License, which permits unrestricted use, distribution, and reproduction in any medium, provided the original work is properly cited.

\section{Introduction}

Nonlinear partial differential equations are encountered in various fields of science. Generalized Burgers-Huxley equation being a nonlinear partial differential equation is of high importance for describing the interaction between reaction mechanisms, convection effects, and diffusion transports. Since there exists no general technique for finding analytical solutions of nonlinear diffusion equations so far, numerical solutions of nonlinear differential equations are of great importance in physical problems.

There are many researchers who used various numerical techniques to obtain numerical solution of the Burgers-Huxley equation. Wang et al. [1] studied the solitary wave solutions of the generalized Burgers-Huxley equation and Estevez [2] presented nonclassical symmetries and the singular modified Burgers and Burgers-Huxley equation. In the past few years, various powerful mathematical methods such as spectral methods [3-5], Adomian 
decomposition method [6-8], homotopy analysis method [9], the tanh-coth method [10], variational iteration method [11, 12], and Hopf-Cole transformation [13] have been used in attempting to solve the equation.

To the best knowledge of the authors, the idea of the differential quadrature method (DQM), where approximations of the spatial derivatives have been based on a polynomial of high degree, has not been implemented for the problems in physical phenomena represented by the generalized Burgers-Huxley equation so far. The DQM is an efficient discretization technique in solving initial and/or boundary value problems accurately using a considerably small number of grid points. Bellman et al. [14] introduced the DQM in the early seventies and, since then, the technique has been successfully employed in finding the solutions of many problems in applied and physical sciences [15-21]. Recent comparative studies show that the DQM provides highly accurate and efficient solutions of the ordinary/partial differential equations taking a noticeably small number of grid points. Due to the aforementioned advantages, the DQM has been projected by its proponents as a potential alternative to the conventional numerical solution techniques such as the finite difference and finite element methods.

In the DQM, derivatives of a function with respect to a coordinate direction are expressed as linear weighted sums of all the functional values at all grid points along that direction. The weighting coefficients in that weighting sum are determined using test functions. Among the many kinds of test functions, the Lagrange interpolation polynomial is widely used since it has no limitation on the choice of the grid points. This leads to polynomial-based differential quadrature (PDQ) method which is suitable in most problems. For periodic problems, Fourier series expansion can be the best approximation giving the Fourier expansion-based differential quadrature (FDQ) method. To clearly describe the DQ method, the readers can see that the PDQ method was first presented in the work of Shu and Richards [18], and FDQ method was first appeared in the works of Shu and Chew [22], and Shu and Xue [23]. The determination of weighting coefficients in explicit formulations [24] for both cases is based on the analysis of function approximation and analysis of a linear vector space.

Unlike some previous techniques using various transformations to reduce the equation into more simple equation, the current method does not require extra effort to deal with the nonlinear terms. Therefore the equations are solved easily and elegantly using the present method. This method has also additional advantages over some rival techniques, ease in use and computational costeffectiveness in order to find solutions of the given nonlinear equations. The combination of the PDQ method in space with the low-storage third-order total variation diminishing Runge-Kutta (TVD-RK3) scheme in time [25] provides an efficient explicit solution with high accuracy and minimal computational effort for the problems represented by the generalized Burgers-Huxley equation.

The present method is useful for obtaining numerical approximations of linear or nonlinear differential equations and it is also quite straightforward to write codes in any programming languages. Also, round off errors and necessity of large computer memory are not faced in this method. The computed results obtained by this way have been compared with the exact solution to show the required accuracy of it. Furthermore, the current method is of a general nature and can therefore be used for solving the nonlinear partial differential equations arising in various areas. Therefore, this paper suggests the use of this technique for solving the generalized Burgers-Huxley equation problems. 


\section{The Model Equation}

Behaviors of many physical systems encountered in models of reaction mechanisms, convection effects, and diffusion transports give rise to the generalized Burgers-Huxley equation. The following generalized Burgers-Huxley equation problem arising in various fields of science is considered:

$$
u_{t}+\alpha u^{\delta} u_{x}-u_{x x}=\beta u\left(1-u^{\delta}\right)\left(u^{\delta}-\gamma\right), \quad 0 \leq x \leq 1, t \geq 0
$$

with the initial condition

$$
u(x, 0)=\left(\frac{\gamma}{2}+\frac{\gamma}{2} \tanh \left(a_{1} x\right)\right)^{1 / \delta}
$$

and the boundary conditions

$$
\begin{aligned}
& u(0, t)=\left(\frac{\gamma}{2}+\frac{\gamma}{2} \tanh \left(-a_{1} a_{2} t\right)\right)^{1 / \delta}, \quad t \geq 0, \\
& u(1, t)=\left(\frac{\gamma}{2}+\frac{\gamma}{2} \tanh \left[a_{1}\left(1-a_{2} t\right)\right]\right)^{1 / \delta}, \quad t \geq 0 .
\end{aligned}
$$

The exact solution of (2.1) is

$$
u(x, t)=\left(\frac{\gamma}{2}+\frac{\gamma}{2} \tanh \left[a_{1}\left(x-a_{2} t\right)\right]\right)^{1 / \delta}, \quad t \geq 0
$$

where

$$
\begin{gathered}
a_{1}=\frac{-\alpha \delta+\delta \sqrt{\alpha^{2}+4 \beta(1+\delta)}}{4(1+\delta)} \gamma \\
a_{2}=\frac{\gamma \alpha}{1+\delta}-\frac{(1+\delta-\gamma)\left(-\alpha+\sqrt{\alpha^{2}+4 \beta(1+\delta)}\right)}{2(1+\delta)}
\end{gathered}
$$

where $\alpha, \beta, \gamma$, and $\delta$ are parameters that $\beta \geq 0, \delta>0$. The role of the parameters on exact solutions was analyzed by Efimova and Kudryashov [13]. If $\beta=0,(2.1)$ reduces to Burgers' equation. When $\alpha=0$, it is the Fitzhugh-Nagoma equation [26, 27].

The current work aims to demonstrate that the proposed numerical algorithm is capable of achieving high accuracy for the problems represented by the generalized BurgersHuxley equation. The computed results are compared with the exact solutions to verify the effectiveness of the current method. 


\section{Polynomial-Based Differential Quadrature Method}

The method uses the basis of the quadrature method in driving the derivatives of a function. It follows that the partial derivative of a function with respect to a space variable can be approximated by a weighted linear combination of function values at some intermediate points in that variable.

The selection of locations of the sampling points plays an important role in the accuracy of the solution of the differential equations. Using uniform grids can be considered to be a convenient and easy selection method. Quite frequently, the DQM delivers more accurate solutions using the so-called Chebyshev-Gauss-Lobatto points [20,24]. For a domain specified by $a \leq x \leq b$ and discretized by a set of nonuniform grids, then the coordinate of any point $i$ can be evaluated by

$$
x_{i}=a+\frac{1}{2}\left(1-\cos \left(\frac{i-1}{N-1} \pi\right)\right)(b-a) .
$$

The values of function $u(x, t)$ at any time on the above grid points are given as $u\left(x_{i}, t\right), i=$ $1,2, \ldots, N$. Here $N$ stands for the number of grid points. The differential quadrature discretizations of the first- and second-order spatial derivatives are given by, respectively:

$$
\begin{aligned}
& u_{x}\left(x_{i}, t\right)=\sum_{j=1}^{N} a_{i j} u\left(x_{j}, t\right), \quad i=1,2, \ldots, N, \\
& u_{x x}\left(x_{i}, t\right)=\sum_{j=1}^{N} b_{i j} u\left(x_{j}, t\right), \quad i=1,2, \ldots, N
\end{aligned}
$$

where $a_{i j}$ and $b_{i j}$ are the weighting coefficients of the first- and second-order derivatives, respectively [24]. Once the weighting coefficients are determined, the bridge to link the derivatives in the governing differential equation and the functional values at the mesh points is established. The weighting coefficients of the first-order derivatives are as follows [24]:

$$
\begin{gathered}
a_{i j}=\frac{1}{x_{j}-x_{i}} \prod_{k=1, k \neq i, j}^{N} \frac{x_{i}-x_{k}}{x_{j}-x_{k}}, \quad i \neq j, \\
a_{i i}=-\sum_{j=1, j \neq i}^{N} a_{i j} .
\end{gathered}
$$

For weighting coefficients of the second = order derivative, the formulae are [24]:

$$
\begin{gathered}
b_{i j}=2 a_{i j}\left(a_{i i}-\frac{1}{x_{i}-x_{j}}\right), \quad i \neq j, \\
b_{i i}=-\sum_{j=1, j \neq i}^{N} b_{i j} .
\end{gathered}
$$


In order to attain the accurate numerical solution of differential equations, proper implementation of the boundary is also very important. For prescribing the Dirichlet boundary conditions (2.3), (2.1) should only be applied at the interior points since the solution at the boundary grid points is known. Thus, (2.1) can be written in discretized form

$$
\frac{d u_{i}}{d t}=\beta u_{i}\left(1-u_{i}^{\delta}\right)\left(u_{i}^{\delta}-\gamma\right)-\alpha u_{i}^{\delta} \sum_{k=1}^{N} a_{i k} u_{k}+\sum_{k=1}^{N} b_{i k} u_{k}+s_{i}, \quad i=2,3, \ldots, N-1,
$$

where

$$
s_{i}=-\alpha u_{i}^{\delta} a_{i 1} u_{1}-\alpha u_{N}^{\delta} a_{i N} u_{N}+b_{i 1} u_{1}+b_{i N} u_{N}
$$

After the discretization, using the PDQ method, (3.5) can be reduced into a set of ordinary differential equations in time. Thus,

$$
\frac{d u_{i}}{d t}=L u_{i}
$$

where $L$ shows a spatial nonlinear differential operator. The low-storage explicit TVD-RK3 scheme integrates from time $t_{0}($ step $m)$ to $t_{0}+\Delta t$ (step $\left.m+1\right)$ through the operations [26]

$$
\begin{aligned}
u_{i}^{(1)} & =u_{i}^{m}+\Delta t L u_{i}^{m}, \\
u_{i}^{(2)} & =\frac{3}{4} u_{i}^{m}+\frac{1}{4} u_{i}^{(1)}+\frac{1}{4} \Delta t L u_{i}^{(1)}, \\
u_{i}^{m+1} & =\frac{1}{3} u_{i}^{m}+\frac{2}{3} u_{i}^{(2)}+\frac{2}{3} \Delta t L u_{i}^{(2)} .
\end{aligned}
$$

In this procedure, each spatial derivative on the right hand side of (3.7) was computed with the use of the PDQ method and then the semidiscrete equation (3.7) was solved with the help of the low-storage explicit TVD-RK3 scheme. Thus, the solution is obtained without solving any algebraic system of equations, and requiring neither linearization nor any transformation.

\section{Numerical Illustrations}

In order to see numerically whether the present methodology leads to accurate solutions, the PDQ solutions will be evaluated for some examples of the generalized Burgers-Huxley equations given above. To verify the efficiency, measure its accuracy and the versatility of the PDQ method for the current problem in comparison with the exact solution, absolute error for different values of $\alpha, \beta, \delta$, and $\gamma$ is reported which is defined by

$$
\left|u\left(x_{i}, t_{j}\right)-U\left(x_{i}, t_{j}\right)\right|
$$


Table 1: The absolute errors for various values of $\delta, x$, and $t$ with $\alpha=1, \beta=1, \gamma=0.001$.

\begin{tabular}{cccccc}
\hline$x_{i}$ & $t$ & $\delta=1$ & $\delta=2$ & $\delta=4$ & $\delta=8$ \\
\hline \multirow{3}{*}{$x_{3}$} & 0.20 & $6.841 \mathrm{E}-09$ & $3.194 \mathrm{E}-07$ & $2.239 \mathrm{E}-06$ & $6.058 \mathrm{E}-06$ \\
& 0.60 & $7.733 \mathrm{E}-09$ & $3.610 \mathrm{E}-07$ & $2.531 \mathrm{E}-06$ & $6.842 \mathrm{E}-06$ \\
& 0.80 & $7.748 \mathrm{E}-09$ & $3.617 \mathrm{E}-07$ & $2.535 \mathrm{E}-06$ & $6.852 \mathrm{E}-06$ \\
$x_{7}$ & 0.20 & $3.644 \mathrm{E}-08$ & $1.701 \mathrm{E}-06$ & $1.193 \mathrm{E}-05$ & $3.226 \mathrm{E}-05$ \\
& 0.60 & $4.226 \mathrm{E}-08$ & $1.973 \mathrm{E}-06$ & $1.383 \mathrm{E}-05$ & $3.739 \mathrm{E}-05$ \\
& 0.80 & $4.236 \mathrm{E}-08$ & $1.977 \mathrm{E}-06$ & $1.386 \mathrm{E}-05$ & $3.746 \mathrm{E}-05$ \\
$x_{13}$ & 0.20 & $1.420 \mathrm{E}-08$ & $6.630 \mathrm{E}-07$ & $4.649 \mathrm{E}-06$ & $1.257 \mathrm{E}-05$ \\
& 0.60 & $1.615 \mathrm{E}-08$ & $7.538 \mathrm{E}-07$ & $5.284 \mathrm{E}-06$ & $1.428 \mathrm{E}-05$ \\
& 0.80 & $1.618 \mathrm{E}-08$ & $7.553 \mathrm{E}-07$ & $5.294 \mathrm{E}-06$ & $1.431 \mathrm{E}-05$ \\
\hline
\end{tabular}

Table 2: The absolute errors for various values of $\delta, x$, and $t$ with $\alpha=0.1, \beta=0.001, \gamma=0.0001$.

\begin{tabular}{cccccc}
\hline$x_{i}$ & $t$ & $\delta=1$ & $\delta=2$ & $\delta=4$ & $\delta=8$ \\
\hline \multirow{3}{*}{$x_{3}$} & 0.10 & $4.059 \mathrm{E}-14$ & $5.984 \mathrm{E}-12$ & $7.554 \mathrm{E}-11$ & $2.802 \mathrm{E}-10$ \\
& 0.50 & $5.888 \mathrm{E}-14$ & $8.681 \mathrm{E}-12$ & $1.096 \mathrm{E}-10$ & $4.065 \mathrm{E}-10$ \\
& 1.00 & $5.924 \mathrm{E}-14$ & $8.733 \mathrm{E}-12$ & $1.102 \mathrm{E}-10$ & $4.090 \mathrm{E}-10$ \\
$x_{7}$ & 0.10 & $2.021 \mathrm{E}-13$ & $2.979 \mathrm{E}-11$ & $3.760 \mathrm{E}-10$ & $1.395 \mathrm{E}-09$ \\
& 0.50 & $3.215 \mathrm{E}-13$ & $4.741 \mathrm{E}-11$ & $5.984 \mathrm{E}-10$ & $2.220 \mathrm{E}-09$ \\
& 1.00 & $3.239 \mathrm{E}-13$ & $4.775 \mathrm{E}-11$ & $6.027 \mathrm{E}-10$ & $2.236 \mathrm{E}-09$ \\
$x_{13}$ & 0.10 & $8.301 \mathrm{E}-14$ & $1.224 \mathrm{E}-11$ & $1.545 \mathrm{E}-10$ & $5.731 \mathrm{E}-10$ \\
& 0.50 & $1.229 \mathrm{E}-13$ & $1.812 \mathrm{E}-11$ & $2.288 \mathrm{E}-10$ & $8.487 \mathrm{E}-10$ \\
& 1.00 & $1.237 \mathrm{E}-13$ & $1.824 \mathrm{E}-11$ & $2.302 \mathrm{E}-10$ & $8.541 \mathrm{E}-10$ \\
\hline
\end{tabular}

Table 3: The absolute errors for various values of $\delta, x$, and $t$ with $\alpha=-0.1, \beta=0.1, \gamma=0.001$.

\begin{tabular}{cccccc}
\hline$x_{i}$ & $t$ & $\delta=1$ & $\delta=2$ & $\delta=4$ & $\delta=8$ \\
\hline \multirow{3}{*}{$x_{4}$} & 0.30 & $2.317 \mathrm{E}-09$ & $1.013 \mathrm{E}-07$ & $6.628 \mathrm{E}-07$ & $1.682 \mathrm{E}-06$ \\
& 0.50 & $2.413 \mathrm{E}-09$ & $1.055 \mathrm{E}-07$ & $6.902 \mathrm{E}-07$ & $1.751 \mathrm{E}-06$ \\
& 0.90 & $2.428 \mathrm{E}-09$ & $1.062 \mathrm{E}-07$ & $6.944 \mathrm{E}-07$ & $1.762 \mathrm{E}-06$ \\
$x_{8}$ & 0.30 & $6.580 \mathrm{E}-09$ & $2.878 \mathrm{E}-07$ & $1.882 \mathrm{E}-06$ & $4.776 \mathrm{E}-06$ \\
& 0.50 & $6.899 \mathrm{E}-09$ & $3.017 \mathrm{E}-07$ & $1.974 \mathrm{E}-06$ & $5.007 \mathrm{E}-06$ \\
& 0.90 & $6.950 \mathrm{E}-09$ & $3.039 \mathrm{E}-07$ & $1.988 \mathrm{E}-06$ & $5.043 \mathrm{E}-06$ \\
$x_{12}$ & 0.30 & $3.695 \mathrm{E}-09$ & $1.616 \mathrm{E}-07$ & $1.057 \mathrm{E}-06$ & $2.681 \mathrm{E}-06$ \\
& 0.50 & $3.855 \mathrm{E}-09$ & $1.686 \mathrm{E}-07$ & $1.103 \mathrm{E}-06$ & $2.798 \mathrm{E}-06$ \\
& 0.90 & $3.881 \mathrm{E}-09$ & $1.697 \mathrm{E}-07$ & $1.110 \mathrm{E}-06$ & $2.816 \mathrm{E}-06$ \\
\hline
\end{tabular}

in the point $\left(x_{i}, t_{j}\right)$. Here $u\left(x_{i}, t_{j}\right)$ the solution portraying the behaviors of physical systems is obtained by the present scheme while $U\left(x_{i}, t_{j}\right)$ stands for the exact solution.

Consider the generalized Burgers-Huxley equation in the form (2.1) with the initial condition (2.2), boundary conditions (2.3), and the exact solution (2.4). The results are compared with the exact solution. The numerical computations were performed using nonuniform grids. The current method is quite straightforward to write codes in any programming languages. Here, all computations were carried out using some codes 
Table 4: The absolute errors for various values of $\beta, x$, and $t$ with $\alpha=1, \delta=1, \gamma=0.001$.

\begin{tabular}{cccccc}
\hline$x_{i}$ & $t$ & $\beta=1$ & $\beta=10$ & $\beta=50$ & $\beta=100$ \\
\hline \multirow{3}{*}{$x_{4}$} & 0.30 & $1.545 \mathrm{E}-08$ & $1.854 \mathrm{E}-07$ & $9.807 \mathrm{E}-07$ & $1.989 \mathrm{E}-06$ \\
& 0.50 & $1.608 \mathrm{E}-08$ & $1.930 \mathrm{E}-07$ & $1.021 \mathrm{E}-06$ & $2.071 \mathrm{E}-06$ \\
& 0.90 & $1.618 \mathrm{E}-08$ & $1.942 \mathrm{E}-07$ & $1.027 \mathrm{E}-06$ & $2.082 \mathrm{E}-06$ \\
$x_{8}$ & 0.30 & $4.387 \mathrm{E}-08$ & $5.264 \mathrm{E}-07$ & $2.785 \mathrm{E}-06$ & $5.649 \mathrm{E}-06$ \\
& 0.50 & $4.600 \mathrm{E}-08$ & $5.520 \mathrm{E}-07$ & $2.920 \mathrm{E}-06$ & $5.922 \mathrm{E}-06$ \\
& 0.90 & $4.633 \mathrm{E}-08$ & $5.560 \mathrm{E}-07$ & $2.941 \mathrm{E}-06$ & $5.960 \mathrm{E}-06$ \\
$x_{12}$ & 0.30 & $2.463 \mathrm{E}-08$ & $2.956 \mathrm{E}-07$ & $1.564 \mathrm{E}-06$ & $3.172 \mathrm{E}-06$ \\
& 0.50 & $2.570 \mathrm{E}-08$ & $3.084 \mathrm{E}-07$ & $1.632 \mathrm{E}-06$ & $3.309 \mathrm{E}-06$ \\
& 0.90 & $2.587 \mathrm{E}-08$ & $3.105 \mathrm{E}-07$ & $1.642 \mathrm{E}-06$ & $3.328 \mathrm{E}-06$ \\
\hline
\end{tabular}

Table 5: The absolute errors for various values of $\gamma, x$, and $t$ with $\alpha=5, \beta=10, \delta=2$.

\begin{tabular}{cccccc}
\hline$x_{i}$ & $t$ & $\gamma=10^{-2}$ & $\gamma=10^{-3}$ & $\gamma=10^{-4}$ & $\gamma=10^{-5}$ \\
\hline \multirow{3}{*}{$x_{4}$} & 0.30 & $2.039 \mathrm{E}-04$ & $6.505 \mathrm{E}-06$ & $2.059 \mathrm{E}-07$ & $6.512 \mathrm{E}-09$ \\
& 0.50 & $2.116 \mathrm{E}-04$ & $6.771 \mathrm{E}-06$ & $2.144 \mathrm{E}-07$ & $6.780 \mathrm{E}-09$ \\
& 0.90 & $2.111 \mathrm{E}-04$ & $6.808 \mathrm{E}-06$ & $2.157 \mathrm{E}-07$ & $6.823 \mathrm{E}-09$ \\
$x_{8}$ & 0.30 & $5.809 \mathrm{E}-04$ & $1.848 \mathrm{E}-05$ & $5.848 \mathrm{E}-07$ & $1.849 \mathrm{E}-08$ \\
& 0.50 & $6.071 \mathrm{E}-04$ & $1.937 \mathrm{E}-05$ & $6.131 \mathrm{E}-07$ & $1.939 \mathrm{E}-08$ \\
& 0.90 & $6.064 \mathrm{E}-04$ & $1.950 \mathrm{E}-05$ & $6.175 \mathrm{E}-07$ & $1.953 \mathrm{E}-08$ \\
$x_{12}$ & 0.30 & $3.268 \mathrm{E}-04$ & $1.038 \mathrm{E}-05$ & $3.283 \mathrm{E}-07$ & $1.038 \mathrm{E}-08$ \\
& 0.50 & $3.399 \mathrm{E}-04$ & $1.083 \mathrm{E}-05$ & $3.426 \mathrm{E}-07$ & $1.083 \mathrm{E}-08$ \\
& 0.90 & $3.392 \mathrm{E}-04$ & $1.089 \mathrm{E}-05$ & $3.448 \mathrm{E}-07$ & $1.091 \mathrm{E}-08$ \\
\hline
\end{tabular}

Table 6: Comparison of PDQ-Lagrange and PDQ-Chebyshev methods: the absolute errors for various values of $x$ and $t$ with $\alpha=2, \beta=3, \gamma=0.001, \delta=1$.

\begin{tabular}{cccc}
\hline$x_{i}$ & $t$ & PDQ-Lagrange & PDQ-Chebyshev \\
\hline \multirow{3}{*}{$x_{4}$} & 0.01 & $7.6338863 \mathrm{E}-09$ & $7.6338860 \mathrm{E}-09$ \\
& 0.10 & $3.1524288 \mathrm{E}-08$ & $3.1524290 \mathrm{E}-08$ \\
& 1.00 & $4.6979115 \mathrm{E}-08$ & $4.6979110 \mathrm{E}-08$ \\
$x_{8}$ & 0.01 & $1.0877730 \mathrm{E}-08$ & $1.0877730 \mathrm{E}-08$ \\
& 0.10 & $8.2905812 \mathrm{E}-08$ & $8.2905810 \mathrm{E}-08$ \\
& 1.00 & $1.3450669 \mathrm{E}-07$ & $1.3450670 \mathrm{E}-07$ \\
$x_{12}$ & 0.01 & $9.7652503 \mathrm{E}-09$ & $9.7652500 \mathrm{E}-09$ \\
& 0.10 & $4.9131274 \mathrm{E}-08$ & $4.9131270 \mathrm{E}-08$ \\
& 1.00 & $7.5113908 \mathrm{E}-08$ & $7.5113910 \mathrm{E}-08$ \\
\hline
\end{tabular}

produced in Visual Basic 6.0. $N$ and $\Delta t$ are taken to be 16 and 0.0001 , respectively, in all examples except in Example 4.7. The differences between the computed solution and the exact solution for some values of the constants $\delta, \alpha, \beta$, and $\gamma$ are shown in Tables 1-6. As various problems of science were modelled by nonlinear partial differential equations and since therefore the generalized Burgers-Huxley equation is of great importance, 
Table 7: The maximum absolute errors and convergence rate (CR) of the DQM-TVD-RK3 with $\alpha=5$, $\beta=10, \gamma=2, \delta=1, \Delta t=0.00001, t=0.1$ in Example 4.7 .

\begin{tabular}{lcr}
\hline$N$ & Maximum absolute error & CR \\
\hline 5 & $2.103906 \mathrm{E}-03$ & 14.33 \\
10 & $1.019676 \mathrm{E}-07$ & 18.93 \\
15 & $4.738276 \mathrm{E}-11$ & 16.06 \\
20 & $4.665157 \mathrm{E}-13$ & \\
\hline
\end{tabular}

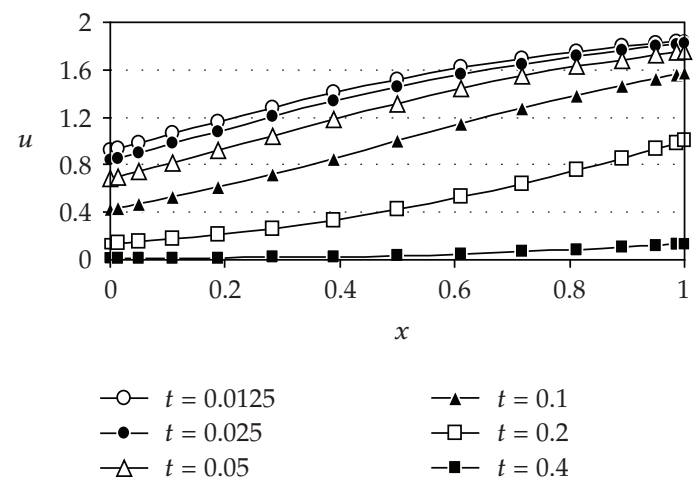

Figure 1: Solutions of Example 4.7 at different times for $\alpha=5, \beta=10, \gamma=2, \delta=1, N=15, \Delta t=0.00001$.

various values of the parameters have been considered in the following examples [4].

Example 4.1. In Table 1, the absolute errors were shown for various values of $\delta, x$, and $t$ with $\alpha=1, \beta=1, \gamma=0.001$. A comparison has been made between the computed and the exact results for various values of the parameters.

Example 4.2. In Table 2, the absolute errors have been shown for various values of $\delta$, $x$, and $t$ with $\alpha=0.1, \beta=0.001, \gamma=0.0001$. A comparison between the exact and the current results is given in Table 2. The obtained results are seen to be very accurate.

Example 4.3. For the computational work in this example, the absolute errors have been shown for various values of $\delta, x$, and $t$ with $\alpha=-0.1, \beta=0.1, \gamma=0.001$. The corresponding results of the parameters have been presented in Table 3. Again accuracy of the present results is clearly seen for the values of the parameters in Table 3.

Example 4.4. Here, the absolute errors have been shown in Table 4 for various values of $\beta, x$, and $t$ with $\alpha=1, \delta=1, \gamma=0.001$. As is the previous examples, the results of the combination of the PDQ method with the low-storage explicit TVD-RK3 have been presented in Table 4. Comparisons of the current results with the exact results showed that the presented results are very accurate.

Example 4.5. Table 5 shows absolute error for various values of $\gamma, x$, and $t$ with $\alpha=5, \beta=10$, $\delta=2$. The results of the present method for the above values of the parameters are shown 
in Table 5. It is important to see from the computed results in Table 5 that the method is very accurate.

Example 4.6. The PDQ method based on the Lagrange interpolation functions and the PDQ method based on the Chebyshev interpolation functions are compared in terms of the absolute errors for various values of $x$ and $t$ with $\alpha=2, \beta=3, \gamma=0.001, \delta=1$ in Table 6. The results in both cases are nearly the same. However, it is important to know that the grid points can be chosen arbitrarily in the case of Lagrange interpolation. This is not the case for the Chebyshev interpolation function, when the problems which are of asymptotic behaviors and need good mesh refinement near the sudden changes take place. This can be easily carried out in the first case while that is not the case in the latter one. Note that the Chebyshev polynomial interpolation function is a good choice for periodic problems.

Example 4.7. The maximum absolute errors and convergence rate (CR) of the proposed method are produced for various values of $N$ with $\alpha=5, \beta=10$, $\gamma=2, \delta=1, \Delta t=0.00001, t=0.1$ in Table 7. Accuracy of the present method is shown by calculating the pointwise rate of convergence. Numerical rate of convergence (CR) has also been studied to know about the convergency of the scheme. The rate of convergence for the scheme is calculated using the following formula:

$$
\text { rate of convergence }(C R) \approx \frac{\log \left(E\left(N_{2}\right) / E\left(N_{1}\right)\right)}{\log \left(N_{1} / N_{2}\right)} \text {, }
$$

where $E\left(N_{j}\right)$ is the maximum absolute error when using the number of grid points $N_{j}$. Also computational orders in Table 7 show the high-order accuracy of the present method for solving such problems. To see the behaviors at various times, the PDQ solutions are exhibited for different times with $\alpha=5, \beta=10, \gamma=2, \delta=1, N=15, \Delta t=0.00001$ in Figure 1.

In the examples above, although a very few number of grids are used and even when the parameters are taken to increase the nonlinearity of the problem, the present results are still seen to be very accurate. Tables 1-6 show that a very good approximation to the actual solution of the equations was achieved by using the method. A very good agreement between the results of the combination of the PDQ with the low-storage explicit TVD-RK3 scheme and exact solution was observed, which confirms the validity of the present method. This method is a very reliable alternative technique to some existing methods which face well-known difficulties.

\section{Conclusions}

In this paper, use of a combination of polynomial-based differential quadrature method in space and a low-storage third-order total variation diminishing Runge-Kutta method in time has been proposed for the generalized Burgers-Huxley equation, with high convergence. Comparisons of the computed results with exact solutions showed that the method has the capability of solving the generalized Burgers-Huxley equation and is also capable of 
producing highly accurate solutions with minimal computational effort for both time and space. It was seen that the polynomial-based differential quadrature technique approximates the exact solution very well. Since the scheme is explicit, linearization is not needed. No requiring extra effort to deal with nonlinear terms, ease in use, and computational costeffectiveness have made the current method an efficient alternative method for modelling these nonlinear behaviors. For concrete problems where an exact solution does not exist, the present method is a very good choice to achieve a high degree of accuracy while dealing with the problems.

\section{References}

[1] X. Y. Wang, Z. S. Zhu, and Y. K. Lu, "Solitary wave solutions of the generalised Burgers-Huxley equation," Journal of Physics A, vol. 23, no. 3, pp. 271-274, 1990.

[2] P. G. Estevez, "Non-classical symmetries and the singular manifold method: the Burgers and the Burgers-Huxley equations," Journal of Physics A, vol. 27, no. 6, pp. 2113-2127, 1994.

[3] M. T. Darvishi, S. Kheybari, and F. Khani, "Spectral collocation method and Darvishi's preconditionings to solve the generalized Burgers-Huxley equation," Communications in Nonlinear Science and Numerical Simulation, vol. 13, no. 10, pp. 2091-2103, 2008.

[4] M. Javidi, "A numerical solution of the generalized Burgers-Huxley equation by spectral collocation method," Applied Mathematics and Computation, vol. 178, no. 2, pp. 338-344, 2006.

[5] M. Javidi and A. Golbabai, "A new domain decomposition algorithm for generalized Burger'sHuxley equation based on Chebyshev polynomials and preconditioning," Chaos, Solitons E Fractals. In press.

[6] I. Hashim, M. S. M. Noorani, and M. R. Said Al-Hadidi, "Solving the generalized Burgers-Huxley equation using the Adomian decomposition method," Mathematical and Computer Modelling, vol. 43, no. 11-12, pp. 1404-1411, 2006.

[7] I. Hashim, M. S. M. Noorani, and B. Batiha, "A note on the Adomian decomposition method for the generalized Huxley equation," Applied Mathematics and Computation, vol. 181, no. 2, pp. 1439-1445, 2006.

[8] H. N. A. Ismail, K. Raslan, and A. A. Abd Rabboh, “Adomian decomposition method for Burger'sHuxley and Burger's-Fisher equations," Applied Mathematics and Computation, vol. 159, no. 1, pp. 291301, 2004.

[9] A. Molabahramia and F. Khani, "The homotopy analysis method to solve the Burgers-Huxley equation," Nonlinear Analysis: Real World Applications, vol. 10, no. 2, pp. 589-600, 2009.

[10] A.-M. Wazwaz, "Analytic study on Burgers, Fisher, Huxley equations and combined forms of these equations," Applied Mathematics and Computation, vol. 195, no. 2, pp. 754-761, 2008.

[11] B. Batiha, M. S. M. Noorani, and I. Hashim, "Application of variational iteration method to the generalized Burgers-Huxley equation," Chaos, Solitons E Fractals, vol. 36, no. 3, pp. 660-663, 2008.

[12] B. Batiha, M. S. M. Noorani, and I. Hashim, "Numerical simulation of the generalized Huxley equation by He's variational iteration method," Applied Mathematics and Computation, vol. 186, no. 2, pp. 1322-1325, 2007.

[13] O. Yu. Efimova and N. A. Kudryashov, "Exact solutions of the Burgers-Huxley equation," Journal of Applied Mathematics and Mechanics, vol. 68, no. 3, pp. 413-420, 2004.

[14] R. Bellman, B. G. Kashef, and J. Casti, "Differential quadrature: a technique for the rapid solution of nonlinear partial differential equations," Journal of Computational Physics, vol. 10, pp. 40-52, 1972.

[15] C. W. Bert and M. Malik, "Differential quadrature method in computational mechanics: a review," Applied Mechanics Review, vol. 49, no. 1, pp. 1-28, 1996.

[16] M. Sari, “Differential quadrature method for singularly perturbed two-point boundary value problems," Journal of Applied Sciences, vol. 8, pp. 1091-1096, 2008.

[17] C. Shu, Generalized differential-integral quadrature and application to the simulation of incompressible viscous flows including parallel computation, Ph.D. thesis, University of Glasgow, Glasgow, UK, 1991.

[18] C. Shu and B.E. Richards, "Application of generalized differential quadrature to solve twodimensional incompressible Navier-Stokes equations," International Journal for Numerical Methods in Fluids, vol. 15, no. 7, pp. 791-798, 1992. 
[19] U. Yücel, "Approximations of Sturm-Liouville eigenvalues using differential quadrature (DQ) method," Journal of Computational and Applied Mathematics, vol. 192, no. 2, pp. 310-319, 2006.

[20] U. Yücel and M. Sari, "Differential quadrature method (DQM) for a class of singular two-point boundary value problems," International Journal of Computer Mathematics, vol. 86, no. 3, pp. 465-475, 2009.

[21] Z. Zong and K. Y. Lam, "A localized differential quadrature (LDQ) method and its application to the 2D wave equation," Computational Mechanics, vol. 29, no. 4-5, pp. 382-391, 2002.

[22] C. Shu and Y. T. Chew, "Fourier expansion-based differential quadrature and its application to Helmholtz eigenvalue problems," Communications in Numerical Methods in Engineering, vol. 13, no. 8, pp. 643-653, 1997.

[23] C. Shu and H. Xue, "Explicit computation of weighting coefficients in the harmonic differential quadrature," Journal of Sound and Vibration, vol. 204, no. 3, pp. 549-555, 1997.

[24] C. Shu, Differential Quadrature and Its Application in Engineering, Springer, London, UK, 2000.

[25] S. Gottlieb and C.-W. Shu, "Total variation diminishing Runge-Kutta schemes," Mathematics of Computation, vol. 67, no. 221, pp. 73-85, 1998.

[26] R. Fitzhugh, "Mathematical models of excitation and propagation in nerve," in Biological Engineering, H. P. Schwan, Ed., pp. 1-85, McGraw-Hill, New York, NY, USA, 1969.

[27] A. L. Hodgkin and A. F. Huxley, "A quantitative description of membrane current and its application to conduction and excitation in nerve," The Journal of Physiology, vol. 117, pp. 500-544, 1952. 


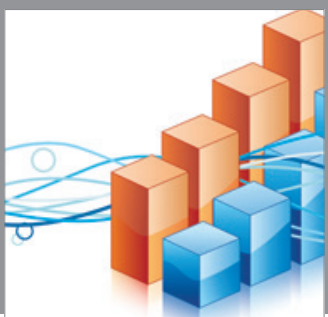

Advances in

Operations Research

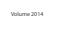

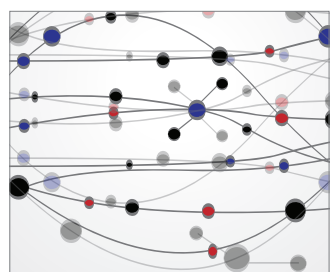

\section{The Scientific} World Journal
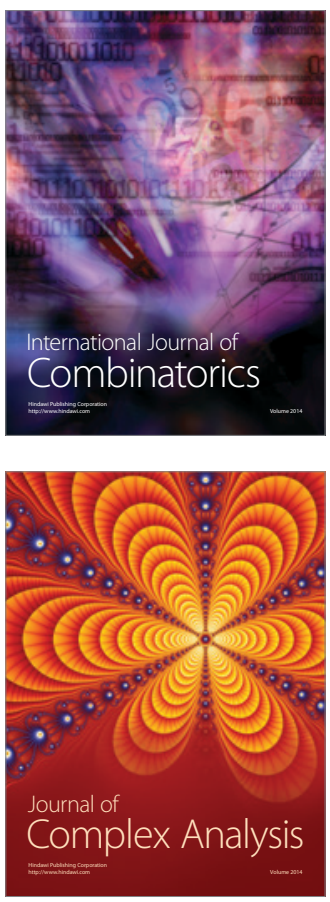

International Journal of

Mathematics and

Mathematical

Sciences
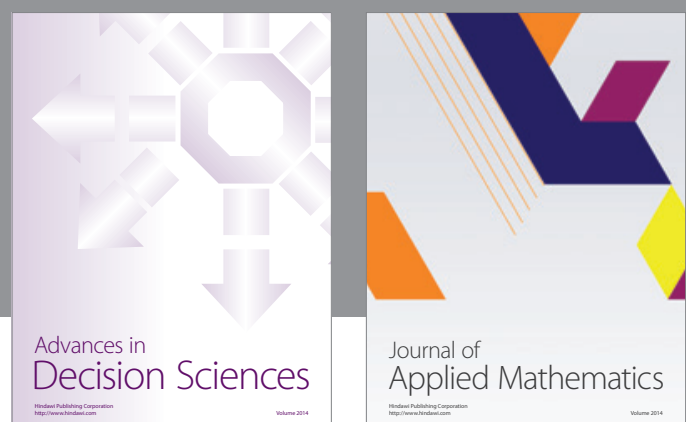

Journal of

Applied Mathematics
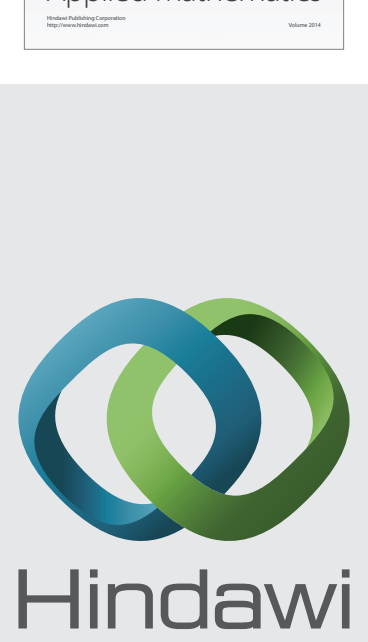

Submit your manuscripts at http://www.hindawi.com
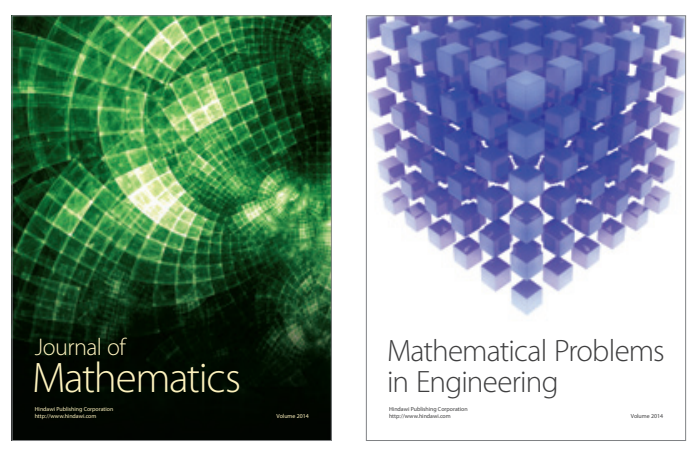

Mathematical Problems in Engineering
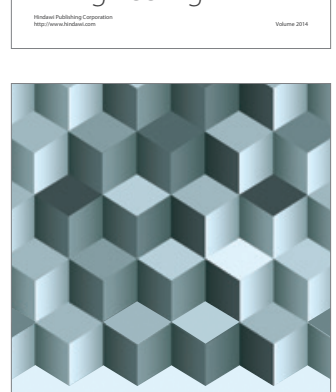

Journal of

Function Spaces
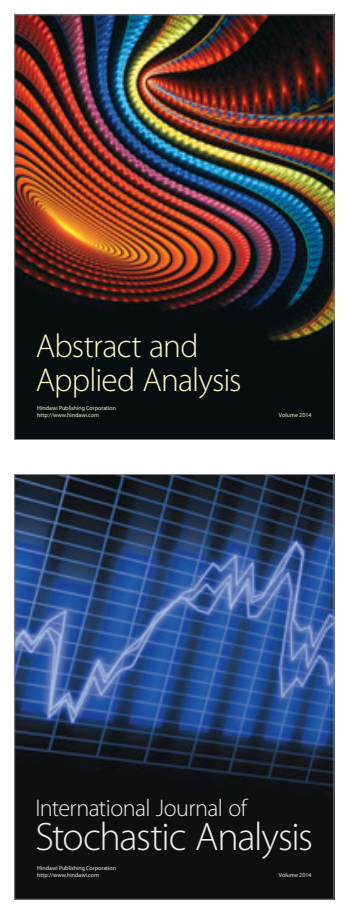

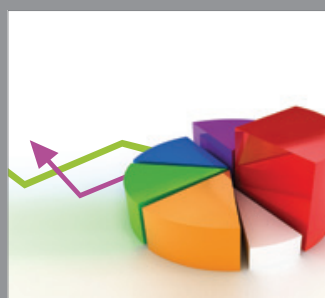

ournal of

Probability and Statistics

Promensencen
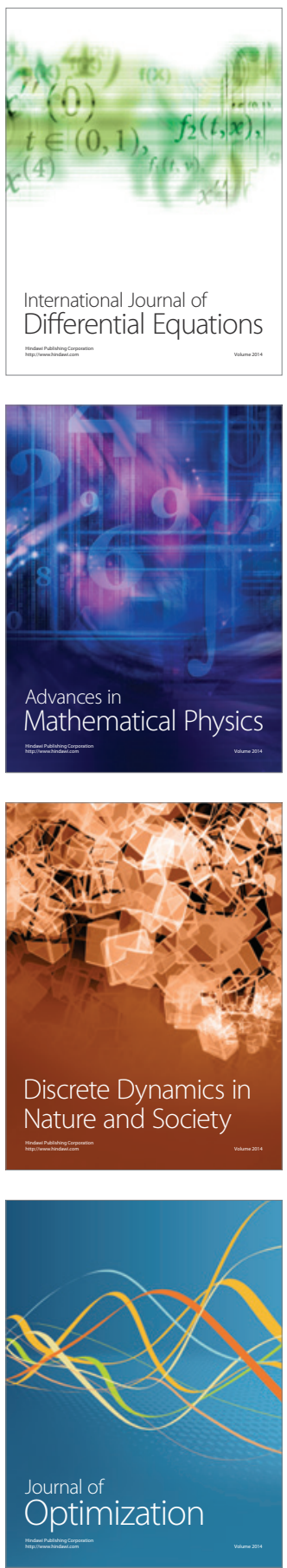